\title{
Learning as a Shared Peak Experience: Interactive Flow in Higher Education
}

\author{
Tim Raettig ${ }^{1,2}$ (D) Ulrich Weger $^{1}$
}

Accepted: 23 June 2018 / Published online: 6 July 2018

(C) Springer International Publishing AG, part of Springer Nature 2018

\begin{abstract}
Student engagement is an important determinant of both academic achievement and subjective well-being. Crucially, engagement has been linked to individuallevel flow, a psychological state characterized by intense enjoyment and complete absorption in an activity. Building on existing concepts, we propose an extension of the flow concept to the group level and argue that teaching is most effective when students working together enter a state of "shared interactive flow" where they communicate effortlessly and facilitate each other's thought processes. Both causes and effects of interactive flow were investigated in a field study based on a newly developed questionnaire. Students from six different undergraduate psychology courses were measured three times during one semester, yielding 341 observations. The experience of interactive flow was highly correlated with interest in course contents, perceived group competence, the amount of own and group verbal contributions, satisfaction and learning success. Differences in measures acquired before and after classes point to the existence of two virtuous circles: group competence and interest facilitate the occurrence of interactive flow which in turn leads to increasing interest and perceptions of higher group competence. In practical terms, this suggests that teachers can make use of these feedback loops by instilling group-level efficacy beliefs in their students and ensuring that the initial topics of a classroom session are particularly captivating.
\end{abstract}

Keywords Interactive flow · Social flow Flow · Student engagement · Learning · Group efficacy beliefs

Tim Raettig

tim.raettig@uni-wuerzburg.de

1 Department of Psychology and Psychotherapy, University of Witten-Herdecke,

Alfred-Herrhausen-Straße 50, 58448 Witten, Germany

2 Department of Psychology, University of Würzburg, Röntgenring 11, 97070 Würzburg, Germany 


\section{Introduction}

Irrespective of both instructors' and students' age, teaching as well as learning can be monotonous and boring, elating and exciting, or anything in between. However, we would like to argue that it is the elusive instances of shared enthusiasm that result in some of the most enjoyable and - as will be discussed below - most effective learning experiences. In the current study, we set out to investigate the antecedents and outcomes of such occurrences, conceptualizing them as cases of "interactive flow" that can be critical for increasing student engagement.

\section{Student Engagement}

Creating an educational environment that fosters student engagement is important because it increases academic achievement, reduces school and university drop-out rates and improves subjective well-being (Archambault et al. 2009; Hirschfield and Gasper 2011; Mills and Fullagar 2008; Park et al. 2012; Sciarra and Seirup 2008; Shernoff et al. 2003; Shernoff and Csikszentmihalyi 2009). Shernoff and Csikszentmihalyi (2009) differentiate two separate aspects of student engagement: academic intensity refers to the amount of concentration, interest and attention that is afforded to a learning task and is related to the level of challenge and personal relevance (e.g., a tough, grade-defining math quiz has high academic intensity). A positive emotional response, on the other hand, is characterized by positive affect, enjoyment and intrinsic motivation and is related to the levels of skill, the amount of control over the situation and how much own activity is involved (e.g., playing a video game can create a positive emotional response).

Shernoff and Csikszentmihalyi (2009) note that both concepts overlap to a large degree with core components of flow (Csikszentmihalyi 1975); in fact, when focusing on individual learning experiences, flow can be understood as an operationalization of engagement (Mills and Fullagar 2008; Shernoff and Csikszentmihalyi 2009). In education, however, flow is a relatively rare occurrence (Csikszentmihalyi and Schneider 2000; Rathunde and Csikszentmihalyi 1993). Remedying this situation - that is, increasing the frequency of flow experiences and thus, student engagement - would be an important contribution towards improving the educational system. In the following, we first briefly outline the antecedents and outcomes of flow during learning, which are already well investigated, but mostly restricted to the level of the individual. We then discuss possible extensions of the concept to social contexts, an area of research that is still in its infancy (Gaggioli et al. 2011; Pierre-Majorique Léger 2013).

\section{The Experience of Flow}

Being in a state of flow (Csikszentmihalyi 1975, 1990, 1997; Csikszentmihalyi and Csikszentmihalyi 1988; Csikszentmihalyi and LeFevre 1989) means having an optimal or peak experience characterized by intense, enjoyable involvement in an activity. Out of up to nine subcomponents of flow that are discussed in the literature (e.g. Rossin et al. 2009; Egbert 2003; Mills and Fullagar 2008), six can be considered as essential (Csikszentmihalyi 1975): clear proximal goals, i.e. there is no doubt about what step needs to be undertaken next; a sense of control over the situation; smooth transitions 
between actions; high concentration; a transformed perception of time where hours pass like minutes; and finally, a merging of action and awareness.

While members of particular occupational groups (namely athletes and artists) have been shown to be especially prone to experience flow (Csikszentmihalyi 1990), flow does occur in all cultures, social classes, and age groups (Guo and Ro 2008). Flow is, however, critically dependent on a match-up of high demands and high skill (Csikszentmihalyi 1997; Csikszentmihalyi et al. 1993). In educational contexts, learner characteristics such as interest (Abbott 2000; Guo and Ro 2008) and curiosity (Egbert 2003; Guo and Ro 2008; Schiefele and Csikszentmihalyi 1994; Webster et al. 1993) also play an important role as antecedents of flow.

In terms of outcomes, flow has been linked to academic achievement and learning success in a number of studies (Csikszentmihalyi 1997; Custodero 2002; Ghani 1995; Konradt et al. 2001, 2003; Rea 2000), covering age groups from elementary school children (Marks 2000; Skinner et al. 1990) over secondary schoolers (Goos et al. 2002; Shernoff et al. 2003) to university students (Guo and Ro 2008; Joo et al. 2015; Kiili 2005; Webster et al. 1993) and including such diverse settings as foreign language classrooms (Egbert 2003), searching for information on websites (Skadberg and Kimmel 2004) and playing educational computer games (Kiili 2005). Note, however, that in some cases, the association between flow and (apparent) learning success has been shown to be due to the subjective (mis)perception of increased learning rather than actually increased learning (Rossin et al. 2009). Looking beyond the purely intellectual level, flow can also foster personal growth and development in general (Shernoff et al. 2003; Shernoff and Csikszentmihalyi 2009): since demanding tasks are better suited to induce flow and flow is an inherently enjoyable experience, striving to get into a flow state can motivate people to seek new and harder challenges once they have acquired a particular skill set, resulting in continued self-improvement.

\section{Flow in Social Contexts}

Traditionally, flow has been understood as a state on the level of the individual. However, both the genesis (Salanova et al. 2014; Sawyer 2003, 2008) and the affective appraisal of flow (Walker 2010) can be influenced by the presence of others. For example, the flow-derived enjoyment of a runner in a marathon may be increased when he realizes that the people around him share his delight. In this scenario, the social context is simply a background phenomenon: it affects how the flow state feels, but it is not causal to its emergence. A different runner in the same marathon, however, may be so distracted by the presence of his competitors that he does not attain a state of flow at all - for him, the presence of co-participants (or even mere observers) is a causal factor preventing the development of flow. A third runner, on the other hand, may never feel flow when jogging on his own, but only when he has to navigate through a crowd of other athletes - for him, the social context is promoting the experience of flow.

Note that in all three scenarios, flow - while being affected by social variables - still only refers to the psychological state of one individual. However, it is also possible to conceptualize flow as the state of an entire group (Sawyer 2003, 2008). For example, musicians in a band sometimes seem to perform in almost perfect synchrony: here, the group being in flow is dependent on the actions of one person following seamlessly 
from the actions of another person, on a level that is distinctly beyond that of any single group member.

In the existing literature, the terminology for flow beyond the individual level is heterogeneous: 'group flow' is a label that is used relatively frequently (Armstrong 2008; Hart and Blasi 2015; Salanova et al. 2014; Sawyer 2003), but competes with 'social flow' (Salanova et al. 2014; Walker 2010), 'shared flow' (Hart and Blasi 2015; Salanova et al. 2014), 'collective flow' (Salanova et al. 2014), 'co-flow' (Salanova et al. 2014), 'team flow' (Heyne et al. 2011) and 'combined flow' (Hart and Blasi 2015). As a first step towards more conceptual clarity, we propose a categorization into 'individual flow', 'solitary flow', 'social flow', 'co-active flow', 'interactive flow' and 'group flow' which will be elaborated upon in the following paragraph (also see Fig. 1).

'Individual flow' corresponds to the traditional concept of flow as it is most frequently discussed in the literature (Csikszentmihalyi 1975, 1990, 1997; Csikszentmihalyi and Csikszentmihalyi 1988; Csikszentmihalyi and LeFevre 1989) and covers all forms of flow that can be conceptualized as psychological states of individual persons. In contrast to this, 'group flow' refers to an emergent state of groups that has no equivalent on the individual level. Individual flow occurring in the absence of other people is called 'solitary flow' while individual flow experienced while others are around is called 'social flow'. The latter can be further subcategorized into 'coactive' and 'interactive flow'. Co-active flow describes situations where someone is experiencing flow in the presence of others, but there is minimal to no interaction. It is closely related to solitary flow since the social context is mainly a background variable.

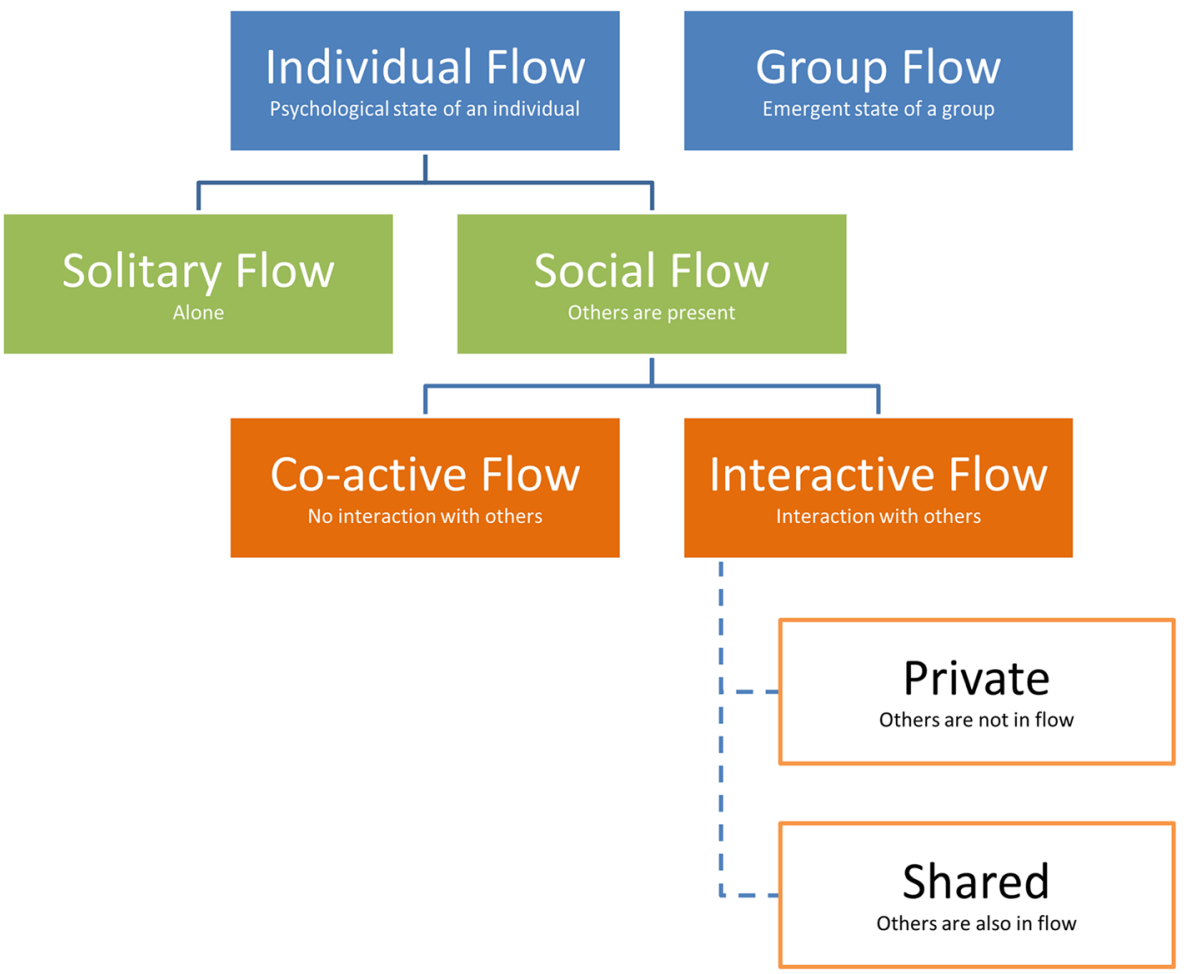

Fig. 1 A taxonomy of flow states 
Interactive flow, on the other hand, occurs when the social context takes center stage and the experience of flow is caused by the interactions that someone has with other persons. Interactive flow is private when these others in turn are not experiencing flow; it is shared when all involved parties are in flow due to their interactions. Since interactive flow is still a form of individual flow, in order for interactive flow to occur, all general conditions for individual flow must be met. However, interacting with others in a group may actually make meeting these conditions easier. For example, as Walker (2010) notes, communicating and coordinating efforts with group members creates additional challenges and can raise the difficulty of otherwise menial tasks to a level that - given sufficient individual skills - is conducive to flow. Similarly, competition with other group members can increase the level of performance that someone aspires to, indirectly increasing both task difficulty and importance. On the other hand, less skilled group members can profit from the expertise of their more knowledgeable peers, thus potentially lowering the difficulty of an otherwise too challenging task into a manageable range.

Education is an inherently social process with interactions on numerous tiers obviously between teachers and learners, but equally importantly among students (Armstrong 2008; Goos et al. 2002), e.g. when learning in small groups. Thus, in this paper, we aim to extend the existing literature on solitary flow in educational contexts by taking a closer look at occurrences of shared interactive flow. Regrettably, the antecedents and outcomes of social flow (in any form) have only been investigated in a small number of studies as of yet (Armstrong 2008; Heyne et al. 2011; Salanova et al. 2014; Sawyer 2003, 2008; Walker 2010). Studies of social flow in educational contexts are even more scarce (Armstrong 2008) and to our knowledge, none exist on the level of higher education. This dearth of empirical evidence is particularly unfortunate because analogous to solitary flow, social flow can be understood as a critical determinant of student engagement and the wealth of positive effects associated with it.

Here, we set out to investigate both causes and effects of social flow (more specifically: shared interactive flow) in a survey-based field study in six undergraduate university courses. We hypothesized that in addition to the well-established antecedents of individual flow in general (Csikszentmihalyi 1997; Csikszentmihalyi et al. 1993), shared interactive flow requires a number of additional pre-conditions to be met: a perception of high competence of the group one is working with (but not necessarily a perception of high own confidence; Salanova et al. 2014); an equally high amount of on-topic contributions of oneself and other group members to the discussion (see below); and the absence of disruptions or communicative dominance by other group members. The two latter hypotheses are derived from the idea that interactive flow can be understood as a self-reinforcing process that is driven by an inherently social urge to receive (positive) feedback for one's ideas. Crucially, this implies at least some degree of balance between the amount of productive (in contrast to disruptive) verbal contributions by different group members, leading to the assumptions outlined above.

In the current study, we also wanted to shed some light on the outcomes of interactive flow in educational environments. We hypothesized that in addition to increasing satisfaction, shared interactive flow would lead to improved learning and heightened interest (Goos et al. 2002) as well as increased perceptions of competence (Salanova et al. 2003, 2014). Since no established measures of shared interactive flow exist, we developed a novel questionnaire by adapting the individual flow scale of 
Rheinberg et al. (2003) which measures components of flow as described by Csikszentmihalyi (1975).

\section{Methods}

\section{Sample and Procedure}

We conducted a field study in six undergraduate psychology classes at the University of Witten-Herdecke (185 participants, 148 female; these were completely different classes, not sections of the same course. Informed consent was obtained from all individual participants). Each class was divided into groups of four to five students. Students were allowed to assign themselves to groups. Groups did not change over the course of the semester. For five classes, data were acquired over three separate sessions (sessions 1, 3 and 5 out of 5) with a four-weeks inter-session gap. One class could only be measured in a single session, yielding a total of 341 observations (session 1: $n=156$; session 3: $n=88$; session 5: $n=97$ ). The authors of this article each taught one of the courses that were part of our sample. The remaining classes were run by colleagues. Sessions lasted $90 \mathrm{~min}$ and consisted of four to five rounds of group work lasting 10-15 min each, interspersed with short (around $5 \mathrm{~min}$ ) plenary debates. We did not supply any specific guidelines to the instructors of the classes. However, the university where this research was conducted makes extensive use of problem-based learning (cf. Wilkerson 1996), meaning that students were quite familiar with working in small groups. In the courses that we taught ourselves, students had to read an academic paper in preparation for each session; they were then given tasks and questions related to that text.

Students filled out two questionnaires per session, one before and one after group work (see below). Both questionnaires could be completed in less than $5 \mathrm{~min}$. We chose to use short questionnaires restricted to the beginning and end of each session in order to keep disruptions of the curriculum to a minimum. We reasoned that it would be acceptable to cut about 10 min per session from regular coursework, but more would put students participating in our study at an unfair disadvantage relative to other classes. Questionnaires were submitted with a consistent, but untraceable pseudonym in order to ensure that students felt free to answer truthfully. Students were told to complete the questionnaires independently from each other.

\section{Measures}

The pre-session questionnaire contained four single-item measures of variables that were hypothesized to have an influence on the occurrence of interactive flow (see Table 1): Pr1, interest (interest in the topic of the session); Pr2, in-group familiarity (familiarity with the other members of the group); Pr3, own competence (expectations regarding one's own competence); Pr4, group competence (expectations regarding the competence of one's group). Items were rated on a nine-point semantic differential scale (Osgood et al. 1957). In the following, these items are called "pre-session antecedents" of interactive flow.

The post-session questionnaire started with our newly developed shared interactive flow measure (see Table 2) which was based on the solitary flow questionnaire 
Table 1 Items of the pre-session questionnaire

\begin{tabular}{lll}
\hline No & Item & Scale \\
\hline Pr1 & The topic of the session is... & interesting...boring \\
Pr2 & I know the other members of my group... & not well...very well \\
$\operatorname{Pr} 3$ & I think my own competence is... & low...high \\
$\operatorname{Pr} 4$ & I think the competence of my group is... & low...high \\
\hline
\end{tabular}

$\operatorname{Pr}$, pre

developed by Rheinberg et al. (2003). The Rheinberg instrument consists of 10 items measuring the components of flow as described by Csikszentmihalyi (1975) in terms of two underlying latent factors, absorption and smoothness. In order to enable us to measure specific aspects of interactive flow, four items gauging the quality of exchanges with other group members were added to Rheinberg's questionnaire (items IF1, IF2, IF13 and IF14). Since we were particularly interested in flow experiences that were shared within the group, all 14 items of the resulting set were (re)worded so that they referred to the group level (cf. Salanova et al. 2003) and written instructions explicitly informed the participants that they were to assess their group, not only themselves. Items were rated on a seven-point Likert scale (completely disagree...completely agree). Following the interactive flow measure, the post-session questionnaire contained a number of single-item measures (rated on nine-point semantic differential scales) including both potential determinants and hypothesized effects of interactive flow. In the following, we refer to the former as "post-session antecedents" of interactive flow while the latter are called "outcomes" of interactive flow.

Table 2 Items of the interactive flow questionnaire

\begin{tabular}{ll}
\hline No & Item \\
\hline IF1 & We interacted like a well-rehearsed team. \\
IF2 & We had a stimulating discussion. \\
IF3 & We felt the level of challenge was optimal. \\
IF4 & Our thinking was fluid and smooth. \\
IF5 & We felt that time was flying by. \\
IF6 & We had no difficulty concentrating. \\
IF7 & We had our wits about us. \\
IF8 & We were completely absorbed in what we were doing. \\
IF9 & We arrived at the correct conclusions effortlessly. \\
IF10 & We always knew what we had to do next. \\
IF11 & We felt like we had everything under control. \\
IF12 & We forgot everything around us. \\
IF13 & Communication in our group went smoothly. \\
IF14 & We inspired each other with thoughts and ideas. \\
\hline
\end{tabular}

$I F$, interactive flow 
Post-session antecedents were variables that we conceptualized as pre-conditions for the occurrence of interactive flow, but that could only be measured at the end of the session (see Table 3). These were further subcategorized into enablers (the more, the better) and obstacles (the less, the better). The enablers included Po6A, own talkativeness (amount of own verbal contributions) and Po7A, group talkativeness (amount of verbal contributions by the group). The obstacles included Po8A, dominance (dominance by other group members) and Po9A, disruptiveness (disruptions by other group members).

Outcomes were subcategorized into one-time measures and two-time measures. One-time measures included Po1O, satisfaction (overall satisfaction with working in the group) and $\mathrm{Po3O}$, learning (self-assessment of how much a participant had learned during the session). Two-time measures were variables that we hypothesized to both have an impact on the genesis of interactive flow and to be impacted by its occurrence. Thus, these were acquired both pre- and post-session, but conceptualized as antecedents in the former case and outcomes in the latter case. Two-time measures included Po2O, interest (interest in the topic of the session), Po4O, own competence (one's own competence during group work) and Po5O, group competence (competence of one's group during group work).

\section{Results}

\section{Factor Structure, Reliability and Convergence}

All analyses described in this section made use of the largest sample of independent observations that was available (session 1, $n=156$ ). Exploratory factor analysis was carried out using maximum likelihood extraction and an orthogonal (oblimin) rotation. Based on an evaluation of the eigenvalues of the correlation matrix (Guttman 1954; Kaiser 1960), we chose to compute a three-factor solution. As can be seen from Table 4, factor loadings were acceptable (following convention, we consider a loading of 0.3 as the minimum for assigning an item to a factor; Child 2006) and

Table 3 Items of the post-session questionnaire

\begin{tabular}{lll}
\hline No & Item & Scale \\
\hline Po1O & I am ... with working in my group & satisfied...dissatisfied \\
Po2O & The topic of the session was... & interesting...boring \\
Po3O & I have learned ... today & a lot...very little \\
P04O & I think my own competence was... & low...high \\
Po5O & I think the competence of my group was... & low...high \\
Po6A & I myself talked... & little....a lot \\
Po7A & Other group members talked... & little.... lot \\
Po8A & Some group members dominated the discussion. & disagree...agree \\
Po9A & Some group members were disruptive. & disagree....agree \\
\hline
\end{tabular}

Po, post; $A$, antecedent; $O$, outcome 
Table 4 Exploratory factor analysis (interactive flow scale), session $1(n=156)$

\begin{tabular}{lrrrrr}
\hline Item & ML1 & ML2 & ML3 & h2 & u2 \\
\hline IF1 & 0.16 & 0.85 & -0.24 & 0.76 & 0.24 \\
IF2 & -0.04 & 0.73 & 0.23 & 0.68 & 0.32 \\
IF3 & 0.14 & 0.31 & 0.45 & 0.50 & 0.50 \\
IF4 & 0.56 & 0.23 & 0.16 & 0.59 & 0.41 \\
IF5 & 0.07 & 0.06 & 0.63 & 0.46 & 0.54 \\
IF6 & 0.54 & 0.04 & 0.05 & 0.33 & 0.67 \\
IF7 & 0.79 & -0.08 & 0.10 & 0.63 & 0.37 \\
IF8 & 0.29 & 0.00 & 0.68 & 0.68 & 0.32 \\
IF9 & 0.64 & 0.06 & 0.16 & 0.55 & 0.45 \\
IF10 & 0.76 & 0.00 & -0.11 & 0.54 & 0.46 \\
IF11 & 0.75 & 0.04 & -0.03 & 0.58 & 0.42 \\
IF12 & 0.00 & -0.01 & 0.64 & 0.40 & 0.60 \\
IF13 & 0.04 & 0.84 & -0.02 & 0.72 & 0.28 \\
IF14 & -0.12 & 0.68 & 0.37 & 0.70 & 0.30 \\
SS Loadings & 3.18 & 2.86 & 2.07 & & \\
ML1 & 1.00 & 0.43 & 0.32 & & \\
ML2 & 0.43 & 1.00 & 0.37 & & \\
ML3 & 0.32 & 0.37 & 1.00 & & \\
\hline
\end{tabular}

ML1-ML3l, factors; $h 2$, communality; $u 2$, uniqueness

exceeded the 0.5 level in 13 out of 14 cases. The same was true for item communalities, with the extracted factors explaining more than $50 \%$ of item variance in 10 out of 14 cases. Together, all three factors accounted for $58 \%$ of total variance. Cronbach's alpha for each subscale was high (absorbtion: 0.88 , smoothness: 0.86 , quality of interactions: 0.88 ), indicating good levels of reliability.

The data from our adapted questionnaire retained Rheinberg et al.'s original division into two subscales (smoothness and absorption) with an item distribution that was essentially identical. At the same time, the four items that we added in order to capture communication-specific aspects of interactive flow (items IF1, IF2, IF13 and IF14) were clearly differentiated and loaded onto a novel third factor. Thus, the factor analysis provides initial evidence that the interactive flow scale works as intended and is supplemented meaningfully by our extensions.

Agreement between group members with regard to flow was assessed by computing ICC(1), ICC(2) and $r_{W G(J)}$ (Klein and Kozlowski 2000). Intra-class correlation coefficients were calculated on the basis of a one-way analysis of variance with group membership as the independent variable and participant's individual flow ratings as the dependent variable. An ICC(1) of 0.44 and an ICC(2) of 0.76 (both F's $=4.18, p<0.001$ ) indicated that perceptions of flow were shared to a considerable degree within groups. The same was true for $r_{W G(J)}$ values (computed across all 14 items of the interactive flow scale using random variance from a rectangular distribution), which ranged between 0.84 and 0.99 (median: 0.97 ) for the different groups. 


\section{Correlational Structure}

We analyzed the linear relationships between interactive flow (the sum of items IF1IF14) and items of the pre- and post-session questionnaires by computing the respective Pearson product-moment correlation coefficients for each session separately (see Tables 5, 6 and 7).

While the tables provide an exhaustive account of all correlations in the dataset, Figs. 2, 3 and 4 visualize particularly relevant subsets of co-varying variables as network graphs (Epskamp et al. 2012). Specifically, they distinguish three broad classes of items as discussed in the "Methods" section: 1) pre-session antecedents of interactive flow (Pr1-Pr4, Fig. 2); post-session antecedents of interactive flow (Po6A-Po9A, Fig. 3); outcomes of interactive flow (Po1O-Po5O, Fig. 4). In the following, all statistically significant correlations between interactive flow and other measures in these subsets are discussed.

As can be seen from Fig. 2, two pre-session antecedents were consistently and positively correlated with interactive flow across sessions: interest (Pr1, session 1: $r=$ 0.28 , session 3: $r=0.4$, session 5: $r=0.24)$ and group competence (Pr4, session 1: $r=$ 0.23 , session 3: $r=0.36$, session $5: r=0.26$ ). Although it was strongly correlated with group competence (session 1: $r=0.45$, session 3: $r=0.54$, session 5: $r=0.51$ ), own competence $(\operatorname{Pr} 3)$ was only correlated with interactive flow in session $1(r=0.22)$. Notably, in-group familiarity $(\operatorname{Pr} 2)$ was not correlated with interactive flow at all, but was correlated with group competence in session $3(r=0.23)$ and session $5(r=0.25)$.

Figure 3 illustrates that in terms of post-session antecedents, interactive flow was strongly correlated with both measures of talkativeness across sessions (own talkativeness, Po6A, session 1: $r=0.31$, session 3: $r=0.46$, session 5: $r=0.47$; group talkativeness, Po7A, session 1: $r=0.43$, session 3: $r=0.57$, session 5: $r=0.56$ ). These two, in turn, were correlated in session $3(r=0.27)$ and session $5(r=0.37)$ and own talkativeness was correlated with disruptiveness (Po9A) in session $3(r=0.22)$. Disruptiveness was negatively correlated with interactive flow in session $1(r=-0.34)$ and positively correlated with dominance (Po8A) in sessions $3(r=0.31)$ and $5(r=0.22)$. Dominance was negatively correlated with interactive flow in session $5(r=-0.34)$.

When looking at Fig. 4, it becomes immediately apparent that interactive flow was consistently correlated with all outcome variables across sessions, which in turn were also highly correlated amongst themselves (for the sake of brevity, we only describe the former in the following; see the next paragraph for an attempt at dealing with item intercorrelatedness). Interactive flow was correlated with satisfaction (Po1O, session 1: $r=$ 0.68 , session 3: $r=0.52$, session 5: $r=0.71$ ) and learning (Po3O, session 1: $r=0.52$, session 3: $r=0.59$, session 5: $r=0.44$ ) which were both only measured post-session. In addition, interactive flow was correlated with interest (Po2O, session 1: $r=0.57$, session 3: $r=0.57$, session 5: $r=0.47$ ), own competence (Po4O, session 1: $r=0.6$, session 3: $r=0.46$, session 5: $r=0.51$ ) and group competence (Po5O, session 1: $r=$ 0.63 , session 3: $r=0.59$, session 5: $r=0.65$ ), which were also measured pre-session: here, post-session correlations were considerably stronger across the board.

Since correlations among outcome variables were non-negligible, we also computed partial correlations (denoted as "pr" in the following) within this subset. Here, the effects of other variables were statistically controlled for when looking at the linear relationships between pairs of measures, resulting in a quantification of independent 


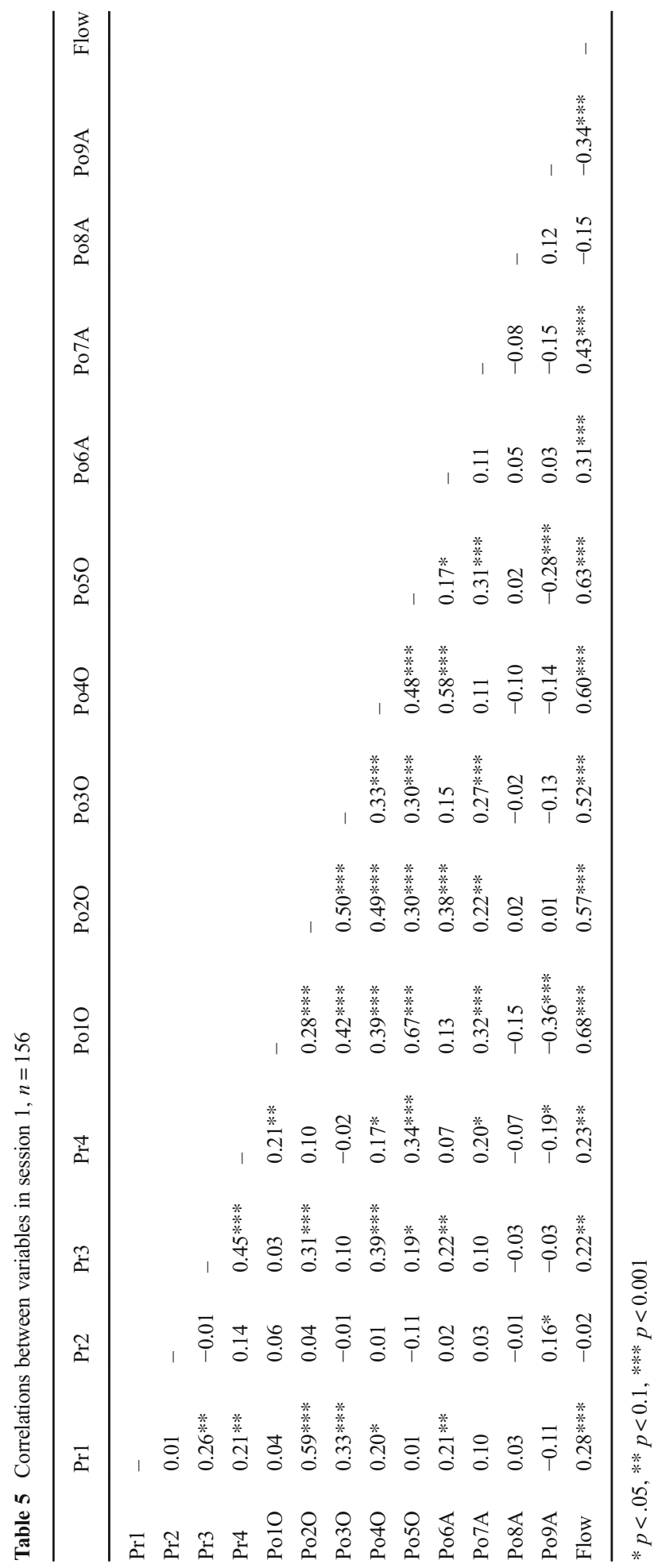




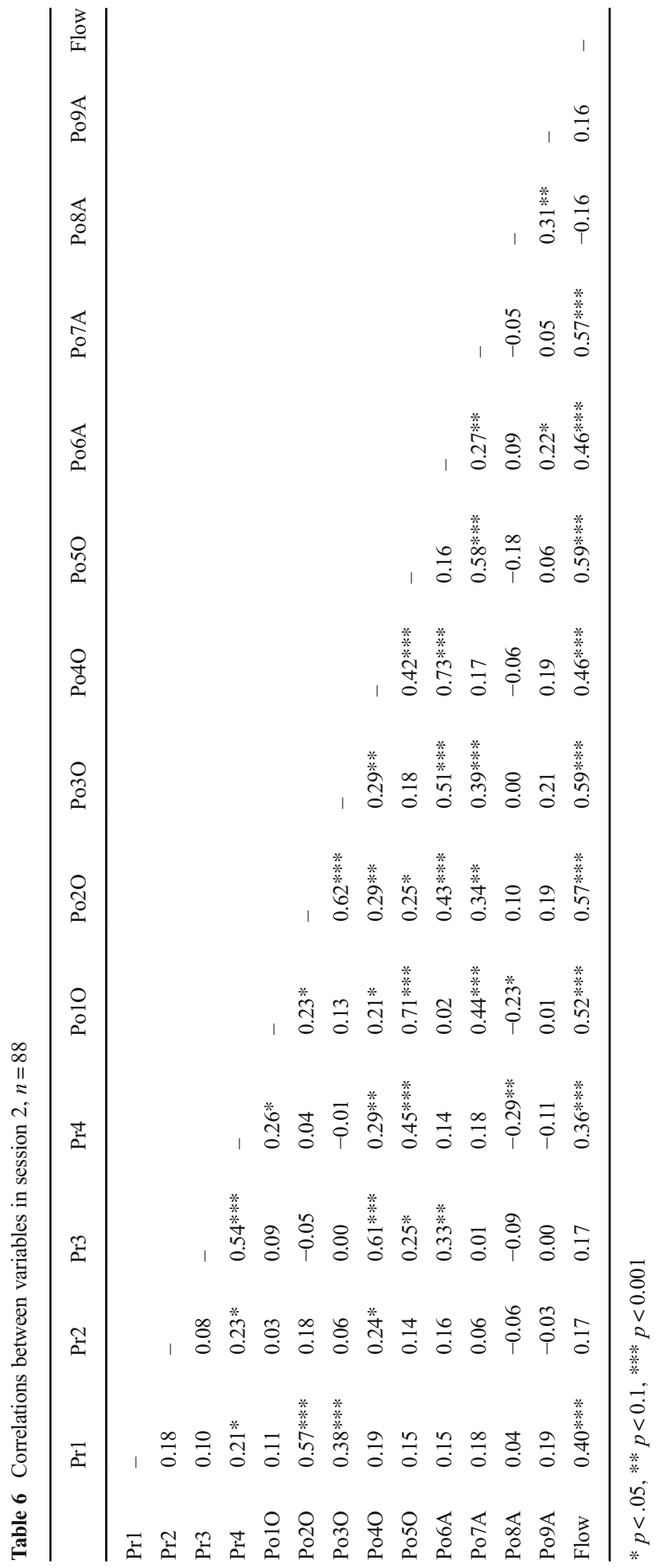




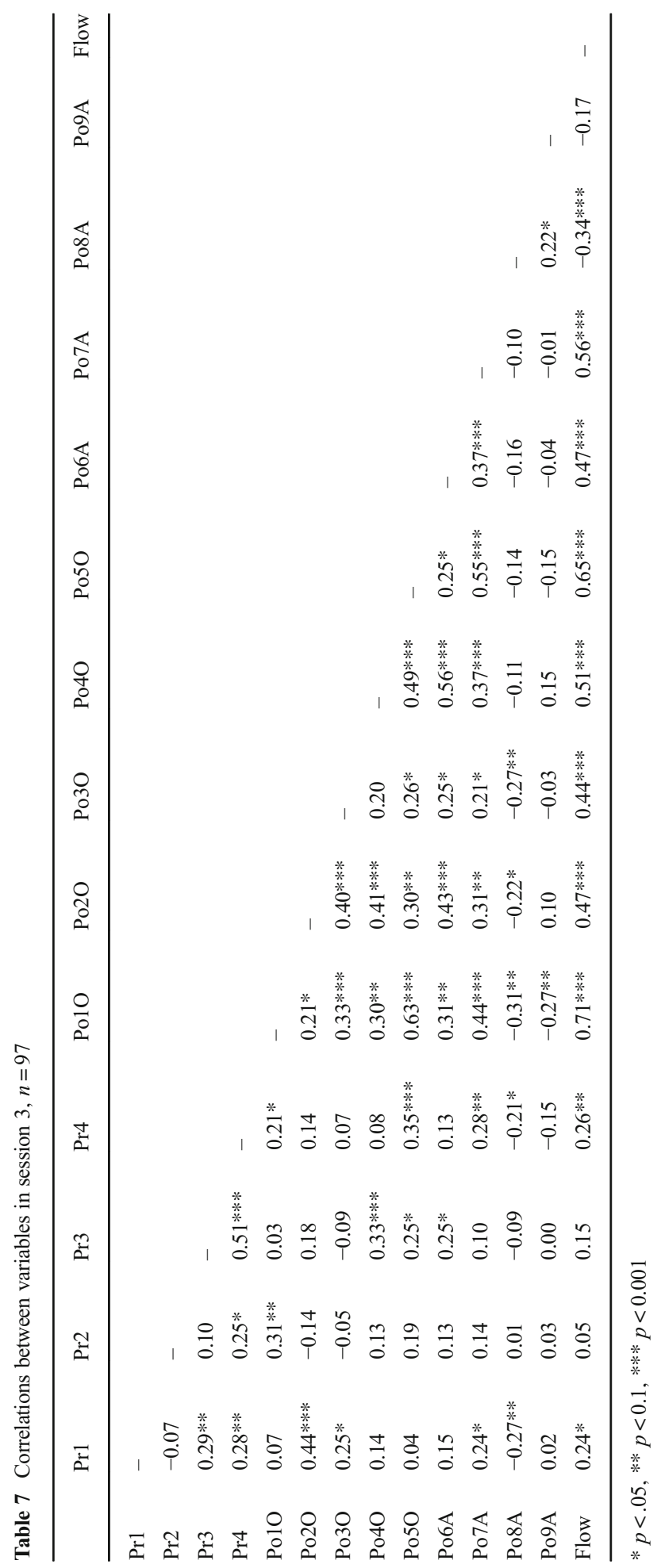



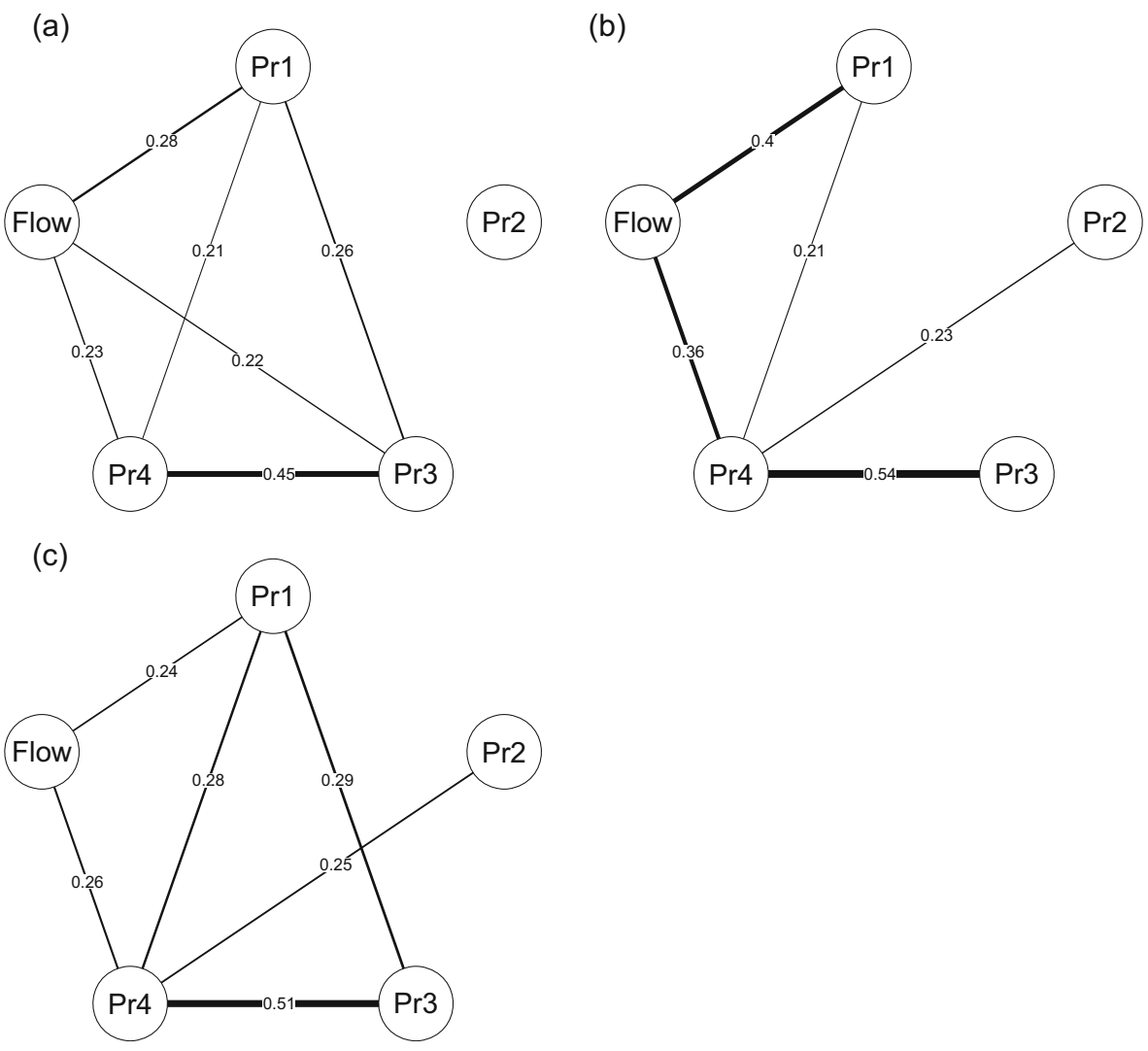

Fig. 2 Correlations between interactive flow and its antecedents as measured pre-session. Line thickness indicates correlation strength. Only correlations with $p<0.05$ are plotted. a session $1, n=156$. b session $3, n=$ 88. c session 5, $n=97$. Pr1, interest; $\operatorname{Pr}$, in-group familiarity; $\operatorname{Pr} 3$, own competence; $\operatorname{Pr} 4$, group competence

covariance with everything else held constant. As can be seen from Fig. 5, the overall pattern of correlations between interactive flow and its outcomes did not change and remained constant across sessions. Interactive flow was correlated with satisfaction (Po1O, session 1: $\mathrm{pr}=0.42$, session 3: $\mathrm{pr}=0.25$, session 5: $\mathrm{pr}=0.52)$, interest $(\mathrm{Po} 2 \mathrm{O}$, session 1: $\mathrm{pr}=0.35$, session 3: $\mathrm{pr}=0.25$, session 5: $\mathrm{pr}=0.28)$, learning $(\mathrm{Po} 3 \mathrm{O}$, session $1: \mathrm{pr}=0.16$, session $3: \mathrm{pr}=0.42)$, own competence $(\mathrm{Po} 4 \mathrm{O}$, session $1: \mathrm{pr}=0.28$, session $5: \mathrm{pr}=0.26)$ and group competence $(\mathrm{Po} 5 \mathrm{O}$, session $1: \mathrm{pr}=0.21$, session $3: \mathrm{pr}=0.27$, session $5: \mathrm{pr}=0.21$ ).

\section{Summary}

The interactive flow questionnaire exhibited the expected factor structure with three subscales. In terms of pre-session measures, interactive flow was correlated with interest and group competence, but not with in-group familiarity. Post-session, interactive flow was correlated with own talkativeness and group talkativeness as antecedents. On the outcome side, interactive flow was correlated with satisfaction, interest, learning, group competence and own competence. Regarding two-time measures (interest, 

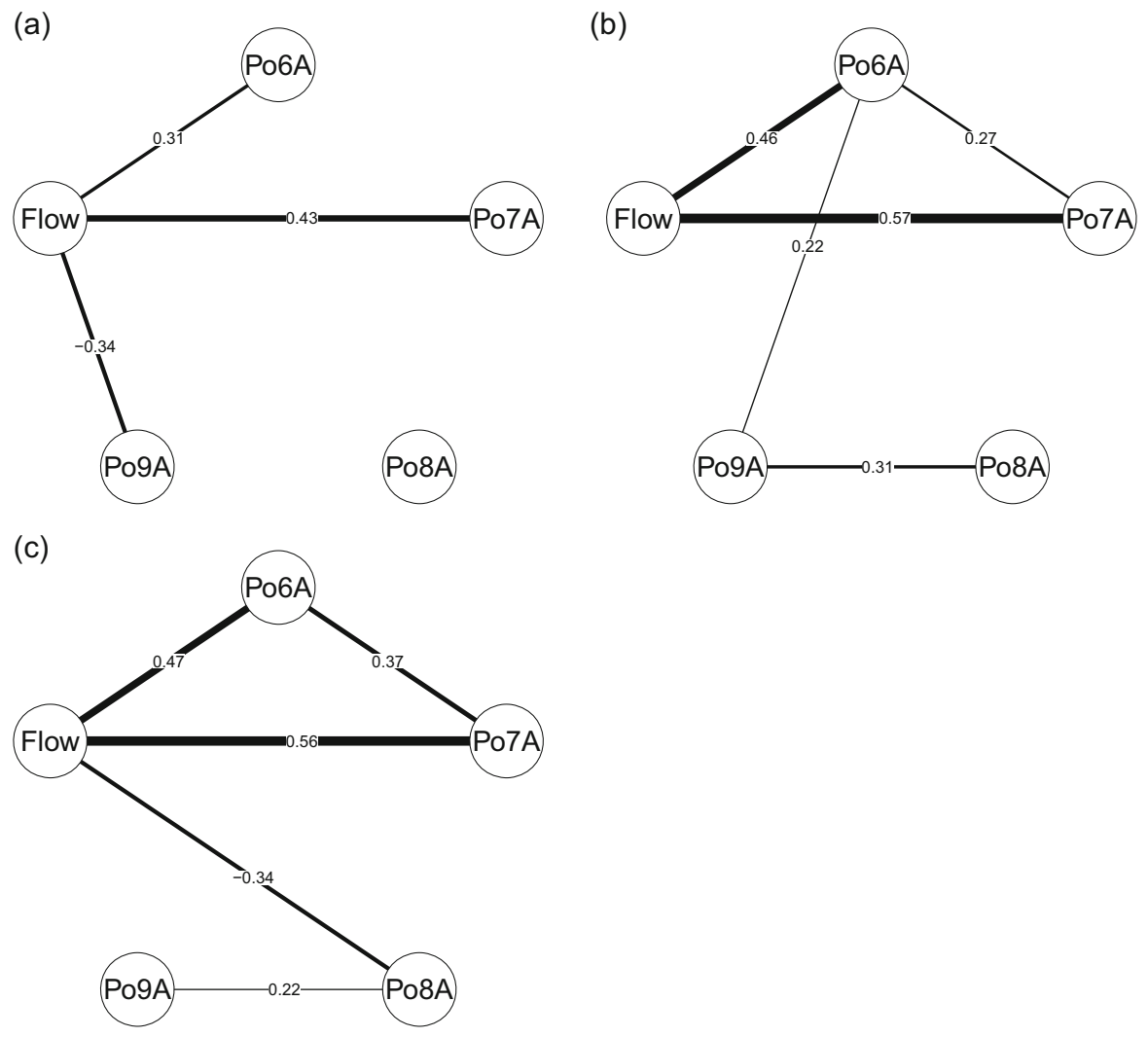

Fig. 3 Correlations between interactive flow and its antecedents as measured post-session. Line thickness indicates correlation strength. Only correlations with $p<0.05$ are plotted. a session $1, n=156$. b session $3, n=$ 88. c session 5, $n=97$. Po6A, own verbal contributions; Po7A, group verbal contributions; Po8A, dominance; Po9A, disturbances

own competence, group competence), post-session correlations with interactive flow (where the variables represent outcomes, not antecedents) were considerably stronger.

\section{Discussion}

In this article, we set out to extend the concept of flow as an operationalization of student engagement to the group level (Mills and Fullagar 2008; Shernoff and Csikszentmihalyi 2009). In order to achieve this, we developed a novel questionnaire measuring shared interactive flow by adapting the individual flow scale of Rheinberg et al. (2003). We then used this instrument to collect data on the antecedents and outcomes of shared interactive flow in a field study in an educational setting.

\section{The Shared Interactive Flow Scale}

As expected, the factor structure of our shared interactive flow questionnaire showed considerable similarities to the original scale that it was built from: the classic flow 

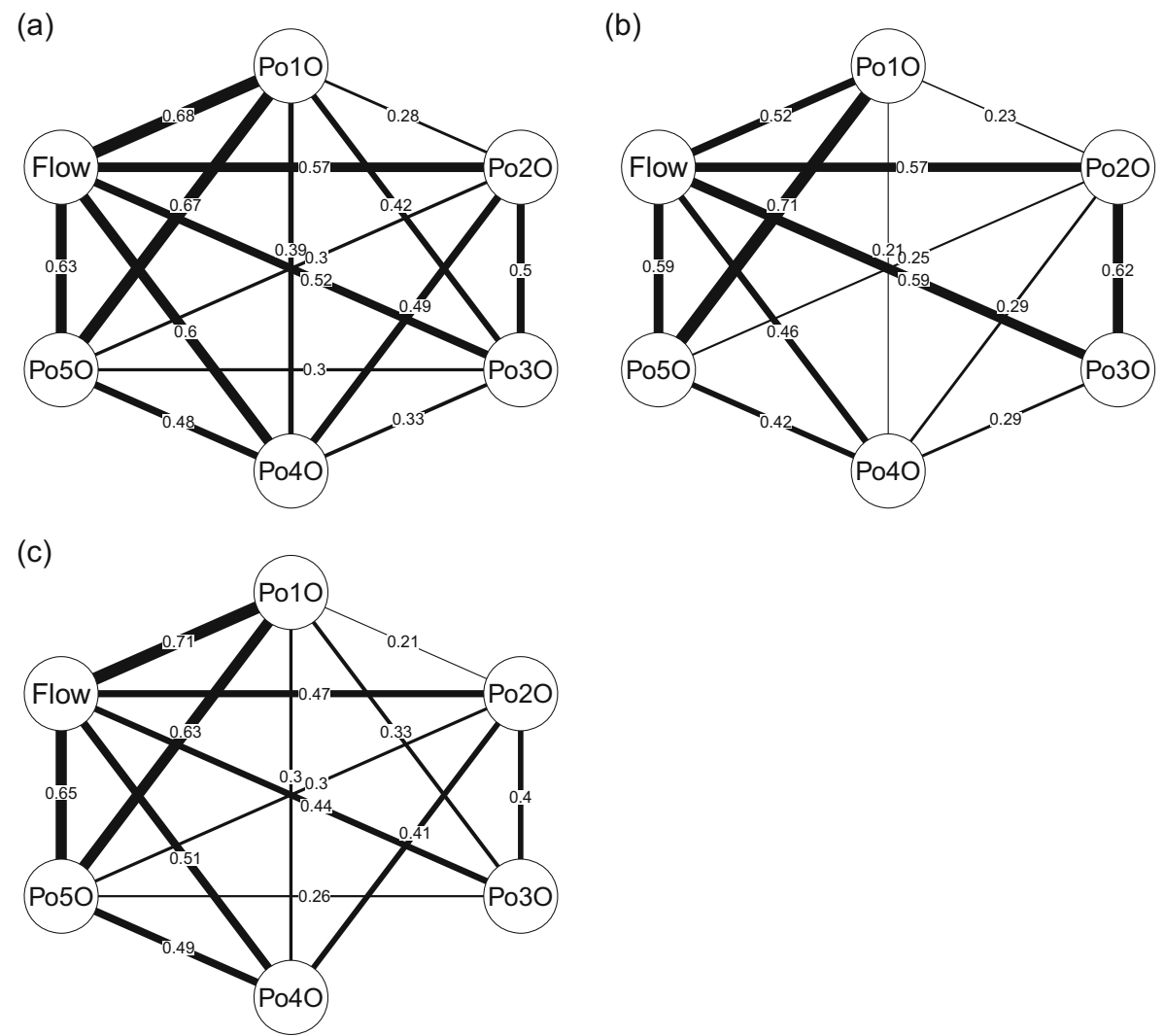

Fig. 4 Correlations between interactive flow and its outcomes. Line thickness indicates correlation strength. Only correlations with $p<0.05$ are plotted. a session $1, n=156$. b session $3, n=88$. c session 5, $n=97$. Po1O, satisfaction; Po2O, interest; Po3O, learning; Po4O, own competence; Po5O, group competence

subscales of absorption and smoothness (Rheinberg et al. 2003) were differentiated cleanly when applied to the group level, too. This is in line with current theorizing in which interactive flow is taken to have core components that are analogous to solitary flow (Salanova et al. 2014), but derive from inter-individual processes. More importantly though, these common subscales were complemented by an interaction-specific subscale based on entirely novel items, capturing aspects of flow in group contexts that would otherwise go unnoticed. We think that our analysis of the dimensionality of the shared interactive flow scale supplies strong initial evidence for the assumption that it meaningfully augments existing individual-level flow scales, constituting an important tool to assess flow as a social phenomenon.

\section{Pre-Session Antecedents of Shared Interactive Flow}

As predicted by contemporary models of flow in groups (Salanova et al. 2014), the level of group competence as perceived by individual members was positively correlated with the subsequent experience of shared interactive flow. Thus, people who expected their group to perform well on the task were more likely to enter an interaction-based flow state. A simple interpretation of this result would be that for 

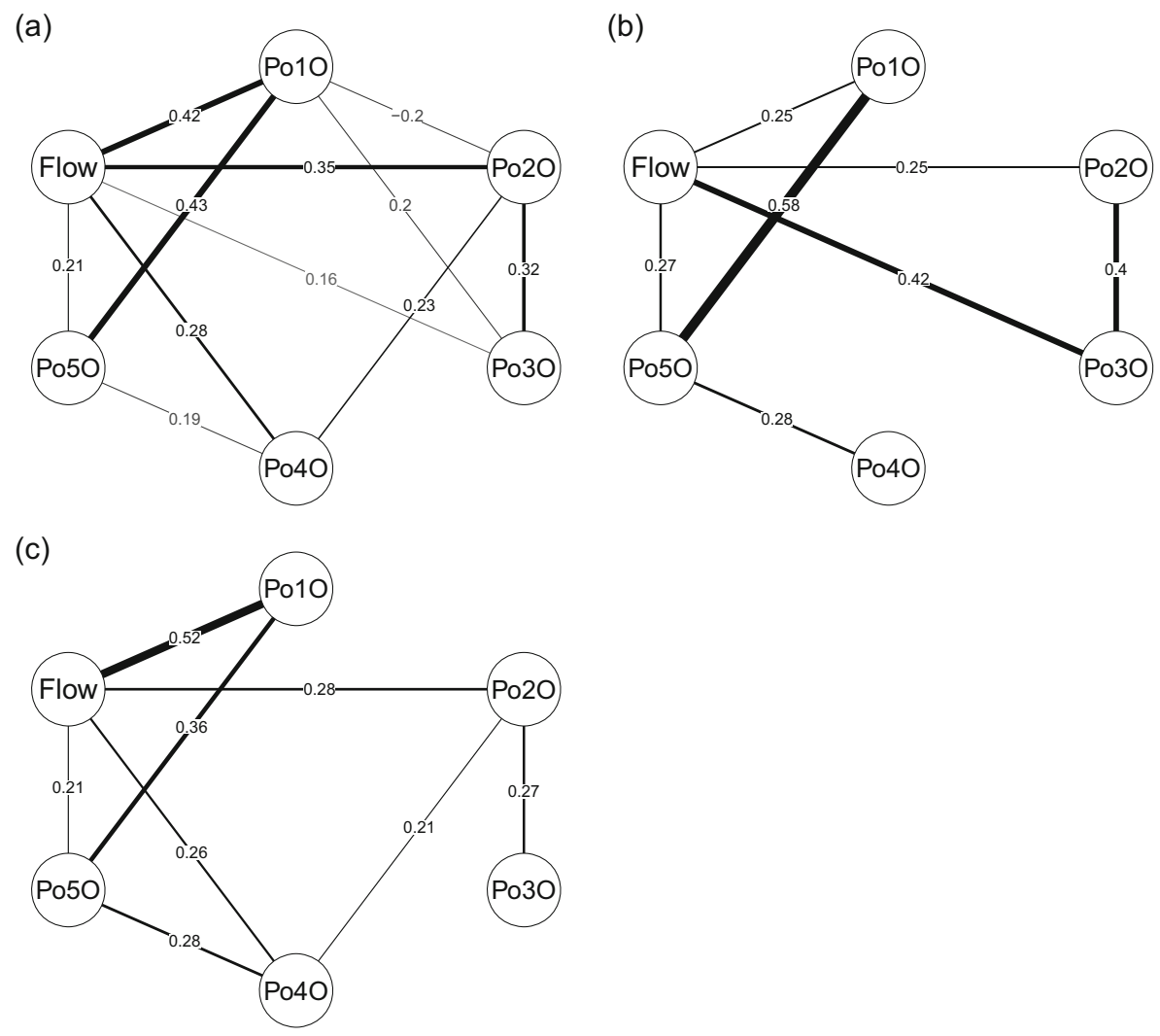

Fig. 5 Partial correlations between interactive flow and its outcomes. Line thickness indicates correlation strength. Only correlations with $p<0.05$ are plotted. a session $1, n=156$. b session $3, n=88$. $\mathbf{c} \operatorname{session} 5, n=$ 97. Po1O, satisfaction; Po2O, interest; Po3O, learning; Po4O, own competence; Po5O, group competence

our groups (which were focusing on an intellectually challenging task), a high level of average member competence was a necessary pre-condition for the occurrence of interactive flow and participants assessed the competence of their peers relatively realistically. A second mechanism that could be at play here, however, is that participants who expected good performance by their group were more motivated to partake in discussions by that very assessment itself - possibly due to an increased desire to get resonance by knowledgeable peers. The resulting increase in the levels of individual activity then led to an increase in the frequency of mutual activations among members of the group, facilitating interactive flow.

Interestingly, there was no comparable correlation between interactive flow and the perceived level of one's own individual competence. Applying the same logic as above, this indicates that either individual competence was not a necessary pre-condition for interactive flow (putting it in strong contrast to solitary flow which has been shown to be dependent on a match-up of high individual skills and a high level of challenge) or participants consistently misjudged themselves. In any case, there is no evidence for a causal link between the expectation of own competence and interactive flow. This stresses the merit of instilling confidence on the group level to maximize learning and performance in educational contexts. 
In addition, interactive flow was positively correlated with the pre-session measure of interest in the topic. Thus, people who found the topic more interesting were more likely to experience interactive flow. In part, this can probably be attributed to a selffulfilling prophecy as was the case with expectations of group performance: the expectation of an interesting session engendered a higher level of motivation for active participation in group discussions, which in turn facilitated the development of interactive flow for all group members - resulting in a more interesting session. At the very least, this is a clear indication that arousing interest in students is of the utmost importance in order to create a pleasant and effective learning environment.

It is also worth mentioning that interactive flow was not consistently correlated with in-group familiarity. Thus, knowing the other group members better did not make it easier to enter a state of interactive flow. While surprising at first, this may be due to the fact that familiarity does not imply compatibility: it is, of course, possible to know someone well but still not get along. Whatever the cause, our data do not indicate that in-group familiarity per se (in contrast to perceived group competence and interest) is beneficial in educational contexts.

\section{Post-Session Antecedents of Shared Interactive Flow}

A number of items that were conceptualized as antecedents of interactive flow were measured post-session because they tapped into aspects of the group discussions that could only be evaluated in retrospect. Here, interactive flow was strongly and positively correlated with both the amount of verbal contributions by oneself and the amount of verbal contributions by other group members. Thus, in contrast to what one would expect with regard to solitary flow, the occurrence of shared interactive flow was not only dependent on a high level of activity by the individual experiencing it, but also on a high level of activity by the rest of the group - as long as that activity was productive in the sense of advancing progress on the task and furthering intra-group communication. Two items measuring disturbances by other group members indicated that not only disruptive behavior, but also communicative dominance by single individuals were obstacles to shared interactive flow. The latter point is particularly interesting because similar to the measures of own and group verbal contributions, it indicates that the balance between individual and group activity is key in terms of facilitating the occurrence of shared interactive flow. This is in line with the idea of mutual resonance and activation playing an important role here as hypothesized in the Introduction.

\section{Outcomes of Shared Interactive Flow}

All items conceptualized as outcomes were highly correlated with shared interactive flow, but were also highly correlated amongst themselves. For this reason, we additionally computed partial correlations between shared interactive flow and the individual outcome items. Nevertheless, the simple correlations are still interesting in terms of analyzing changes from pre- to post-session measurements for items that were acquired two times.

In terms of non-partial correlations, the most striking result was that the assessment of group competence changed over the course of a session (i.e. from the pre-session to the post-session measure) with the post-session measure showing a considerably 
stronger correlation with shared interactive flow across all sessions. This indicates that group efficacy beliefs did not simply co-vary with shared interactive flow and vice versa, but evaluations of group competence changed in proportion to how much shared interactive flow was experienced: otherwise, the correlations for the pre- and postsession measures should be about the same.

We tentatively propose that this is due to the following mechanism: as already discussed above, high pre-session group efficacy beliefs lead to higher motivation to participate in group discussions in order to get resonance, which in turn facilitates the occurrence of shared interactive flow. The interactive flow state then results in higher group performance - and a correspondingly elevated appreciation of group competence, effectively constituting a self-fulfilling prophecy. In terms of practical applicability, this suggests a virtuous circle similar to what has previously been described as "gain cycles", "spirals of efficacy beliefs" and "efficacy-performing spirals" (Lindsley et al. 1995; Salanova et al. 2011): instilling modest levels of group efficacy beliefs in students can considerably facilitate the development of shared interactive flow which in turn can considerably strengthen group efficacy beliefs, and so on. ${ }^{1}$

A similar pattern was observed with regard to correlations between shared interactive flow and pre- versus post-session measures of interest in the topic. As pointed out above, the fact that correlations with the post-session measures were considerably stronger indicates that when the values of the corresponding variables changed during the course of the session, these changes were linked to flow: the experience of more shared interactive flow was associated with proportional increases in interest, hinting at another virtuous circle where interest facilitates interactive flow (due to group members being more motivated to participate in discussions), which in turn results in increasing interest (due to deeper intellectual engagement and more thorough understanding).

In terms of partial correlations, we found a consistently strong positive relationship between shared interactive flow and satisfaction. Thus, as expected, people experience shared interactive flow as something pleasant. More importantly, though, we found a positive partial correlation between shared interactive flow and learning, indicating that academic success can be increased by creating environments that foster vigorous interaction among students. It has to be noted, however, that we were only able to employ a simple self-assessment measure of learning due to pragmatic constraints; it is possible that interactive flow is related to perceptions of learning success more than it is related to actual learning success. Even so, it would at the very least constitute an important determinant of student motivation and self-confidence. Nevertheless, future studies should try to tease apart the subjective perception of learning from objectively measured gains in knowledge (cf. Rossin et al. 2009). For example, this could be achieved by gauging learning with in-depth pre- and post-session quizzes.

\section{Conclusions}

Students can profit immensely from working in small groups. Not only can they scaffold each other's learning processes by entering a collaborative zone of proximal

\footnotetext{
${ }^{1}$ Note that evaluations of one's own competence were only correlated with interactive flow post session, indicating a non-reciprocal relationship.
} 
development (Goos et al. 2002), but experiencing shared interactive flow - a state of mutual resonance and activation where students communicate effortlessly and complement each other's thoughts (Gaggioli et al. 2011, 2012; Sawyer 2003, 2008) significantly improves intellectual engagement. Crucially, this particular form of flow is facilitated by confidence in the competence of one's group, not oneself. Virtuous circles exist regarding both group competence and interest, meaning that on the one hand, they serve as enablers of interactive flow while on the other hand, they are positively affected by it. Thus, our results add to the existing body of knowledge on teaching in general and group work in particular, indicating that e.g. instilling grouplevel efficacy beliefs in students by starting a classroom session with a doable and captivating task can lay the groundwork for tackling something much more difficult and dry.

Acknowledgements The authors wish to thank Anne Böckler for comments and suggestions that greatly improved this manuscript.

\section{Compliance with Ethical Standards}

Conflict of Interest On behalf of all authors, the corresponding author states that there is no conflict of interest.

\section{References}

Abbott, J. A. (2000). "Blinking out" and "having the touch" two fifth-grade boys talk about flow experiences in writing. Written Communication, 17(1), 53-92. https://doi.org/10.1177/0741088300017001003.

Archambault, I., Janosz, M., Fallu, J.-S., \& Pagani, L. S. (2009). Student engagement and its relationship with early high school dropout. Journal of Adolescence, 32(3), 651-670. https://doi.org/10.1016/j. adolescence.2008.06.007.

Armstrong, A. C. (2008). The fragility of group flow: The experiences of two small groups in a middle school mathematics classroom. The Journal of Mathematical Behavior, 27(2), 101-115. https://doi.org/10.1016 j.jmathb.2008.08.001.

Child, D. (2006). Essentials of Factor Analysis (3 Rev ed.). London: Bloomsbury Publishing plc.

Csikszentmihalyi, M. (1975). Beyond boredom and anxiety: Experiencing flow in work and play. San Francisco: Jossey Bass.

Csikszentmihalyi, M. (1990). Flow: The psychology of optimal experience. New York: HarperCollins.

Csikszentmihalyi, M. (1997). Finding flow: The psychology of engagement with everyday life. New York: Basic Books.

Csikszentmihalyi, M., \& Csikszentmihalyi, I. S. (Eds.). (1988). Optimal experience: Psychological studies of flow in consciousness. New York: Cambridge University Press.

Csikszentmihalyi, M., \& LeFevre, J. (1989). Optimal experience in work and leisure. Journal of Personality and Social Psychology, 56(5), 815-822. https://doi.org/10.1037/0022-3514.56.5.815.

Csikszentmihalyi, M., \& Schneider, B. (2000). Becoming adult: How teenagers prepare for the world of work. New York: Basic Books.

Csikszentmihalyi, M., Rathunde, K., Whalen, S., \& Wong, M. (1993). Talented teenagers: The roots of success and failure. New York: Cambridge University Press.

Custodero, L. A. (2002). Seeking challenge, finding skill: Flow experience and music education. Arts Education Policy Review, 103(3), 3-9. https://doi.org/10.1080/10632910209600288.

Rossin, D., Ro, Y.K., Klein, B.D. \& Guo, Y.M. (2009). The effects of flow on learning outcomes in an online information management course. Journal of Information Systems Education, 20(1), 87-98.

Egbert, J. (2003). A study of flow theory in the foreign language classroom. The Modern Language Journal, 87(4), 499-518. https://doi.org/10.1111/1540-4781.00204. 
Epskamp, S., Cramer, A. O. J., Waldorp, L. J., Schmittmann, V. D., \& Borsboom, D. (2012). Qgraph: Network visualizations of relationships in psychometric data. Journal of Statistical Software, 48(4), 1-18.

Gaggioli, A., Milani, L., Mazzoni, E., \& Riva, G. (2011). Networked flow: A framework for understanding the dynamics of creative collaboration in educational and training settings. Open Education Journal, 4(Suppl 2:M2), 107-115.

Gaggioli, A., Riva, G., Milani, L., \& Mazzoni, E. (2012). Networked flow: Towards an understanding of creative networks. Dordrecht: Springer.

Ghani, J. A. (1995). Flow in human computer interactions: Test of a model. In J. M. Carey (Ed.), Human factors in information systems: Emerging theoretical bases (pp. 291-311). Norwood: Ablex Publishing Corp.

Goos, M., Galbraith, P., \& Renshaw, P. (2002). Socially mediated metacognition: Creating collaborative zones of proximal development in small group problem solving. Educational Studies in Mathematics, 49(2), 193-223. https://doi.org/10.1023/A:1016209010120.

Guo, Y. M., \& Ro, Y. K. (2008). Capturing flow in the business classroom. Decision Sciences Journal of Innovative Education, 6(2), 437-462. https://doi.org/10.1111/j.1540-4609.2008.00185.x.

Guttman, L. (1954). Some necessary conditions for common-factor analysis. Psychometrika, 19(2), 149-161. https://doi.org/10.1007/BF02289162.

Hart, E., \& Blasi, Z. D. (2015). Combined flow in musical jam sessions: A pilot qualitative study. Psychology of Music, 43(2), 275-290. https://doi.org/10.1177/0305735613502374.

Heyne, K., Pavlas, D., \& Salas, E. (2011). An investigation on the effects of flow state on team process and outcomes. Proceedings of the Human Factors and Ergonomics Society Annual Meeting, 55(1), 475-479. https://oi.org/10.1177/1071181311551098.

Hirschfield, P. J., \& Gasper, J. (2011). The relationship between school engagement and delinquency in late childhood and early adolescence. Journal of Youth and Adolescence, 40(1), 3-22. https://doi.org/10.1007 /s10964-010-9579-5.

Joo, Y. J., Oh, E., \& Kim, S. M. (2015). Motivation, instructional design, flow, and academic achievement at a Korean online university: A structural equation modeling study. Journal of Computing in Higher Education, 27(1), 28-46. https://doi.org/10.1007/s12528-015-9090-9.

Kaiser, H. F. (1960). The application of electronic computers to factor analysis. Educational and Psychological Measurement, 20, 141-151. https://doi.org/10.1177/001316446002000116.

Kiili, K. (2005). Content creation challenges and flow experience in educational games: The IT-emperor case. The Internet and Higher Education, 8(3), 183-198. https://doi.org/10.1016/j.iheduc.2005.06.001.

Klein, K. J., \& Kozlowski, S. W. J. (2000). From micro to Meso: Critical steps in conceptualizing and conducting multilevel research. Organizational Research Methods, 3(3), 211-236. https://doi.org/10.1177 /109442810033001.

Konradt, U., Sulz, K., Konradt, U., \& Sulz, K. (2001). The experience of flow in interacting with a hypermedia learning environment. Journal of Educational Multimedia and Hypermedia, 10(1), 69-84.

Konradt, U., Filip, R., \& Hoffmann, S. (2003). Flow experience and positive affect during hypermedia learning. British Journal of Educational Technology, 34(3), 309-327. https://doi.org/10.1111/14678535.00329 .

Lindsley, D. H., Brass, D. J., \& Thomas, J. B. (1995). Efficacy-performing spirals: A multilevel perspective. The Academy of Management Review, 20(3), 645-678. https://doi.org/10.5465/AMR.1995.9508080333.

Marks, H. M. (2000). Student engagement in instructional activity: Patterns in the elementary, middle, and high school years. American Educational Research Journal, 37(1), 153-184. https://doi.org/10.3102 /00028312037001153.

Mills, M. J., \& Fullagar, C. J. (2008). Motivation and flow: Toward an understanding of the dynamics of the relation in architecture students. The Journal of Psychology, 142(5), 533-556. https://doi.org/10.3200 /JRLP.142.5.533-556.

Osgood, C. E., Suci, G. J., \& Tannenbaum, P. H. (1957). The measurement of meaning. Oxford: University of Illinois Press.

Park, S., Holloway, S. D., Arendtsz, A., Bempechat, J., \& Li, J. (2012). What makes students engaged in learning? A time-use study of within- and between-individual predictors of emotional engagement in lowperforming high schools. Journal of Youth and Adolescence, 41(3), 390-401. https://doi.org/10.1007 /s10964-011-9738-3.

Léger, P-M., Sénécal, S., Aubé, C., Camero, A-F. (2013). The influence of group flow on group performance: A research program. Proceedings of the Gmunden Retreat on NeuroIS.

Rathunde, K., \& Csikszentmihalyi, M. (1993). Undivided interest and the growth of talent: A longitudinal study of adolescents. Journal of Youth and Adolescence, 22(4), 385-405. https://doi.org/10.1007 /BF01537720. 
Rea, D. W. (2000). Optimal motivation for talent development. Journal for the Education of the Gifted, 23(2), 187-216. https://doi.org/10.4219/jeg-2000-574.

Rheinberg, F., Vollmeyer, R., \& Engeser, S. (2003). Die Erfassung des Flow-Erlebens. In J. StiensmeierPelster \& F. Rheinberg (Eds.), Diagnostik von Motivation und Selbstkonzept (pp. 261-279). Göttingen: Hogrefe.

Salanova, M., Llorens, S., Cifre, E., Martínez, I. M., \& Schaufeli, W. B. (2003). Perceived collective efficacy, subjective well-being and task performance among electronic work groups an experimental study. Small Group Research, 34(1), 43-73. https://doi.org/10.1177/1046496402239577.

Salanova, M., Llorens, S., \& Schaufeli, W. B. (2011). "Yes, I can, I feel good, and I just do it!" on gain cycles and spirals of efficacy beliefs, affect, and engagement. Applied Psychology, 60(2), 255-285. https://doi. org/10.1111/j.1464-0597.2010.00435.x.

Salanova, M., Rodríguez-Sánchez, A. M., Schaufeli, W. B., \& Cifre, E. (2014). Flowing together: A longitudinal study of collective efficacy and collective flow among workgroups. The Journal of Psychology, 148(4), 435-455. https://doi.org/10.1080/00223980.2013.806290.

Sawyer, R. K. (2003). Group Creativity: Music, Theater, Collaboration (Auflage: New.). Mahwah: Psychology Pr.

Sawyer, R. K. (2008). Group genius: The creative power of collaboration. New York: Basic Books.

Schiefele, U., \& Csikszentmihalyi, M. (1994). Interest and the quality of experience in classrooms. European Journal of Psychology of Education, 9(3), 251-269. https://doi.org/10.1007/BF03172784.

Sciarra, D., \& Seirup, H. (2008). The multidimensionality of school engagement and math achievement among racial groups. Professional School Counseling, 11(4), 218-228. https://doi.org/10.5330/PSC. n.2010-11.218.

Shernoff, D., \& Csikszentmihalyi, M. (2009). Flow in schools: Cultivating engaged learners and optimal learning environments. In R. Gilman, E. S. Huebner, \& M. Furlong (Eds.), Handbook of positive psychology in schools (pp. 131-145). New York: Routledge.

Shernoff, D., Csikszentmihalyi, M., Shneider, B., \& Shernoff, E. S. (2003). Student engagement in high school classrooms from the perspective of flow theory. School Psychology Quarterly, 18(2), 158-176. https://doi.org/10.1521/scpq.18.2.158.21860.

Skadberg, Y. X., \& Kimmel, J. R. (2004). Visitors' flow experience while browsing a web site: Its measurement, contributing factors and consequences. Computers in Human Behavior, 20(3), 403-422. https://doi.org/10.1016/S0747-5632(03)00050-5.

Skinner, E. A., Wellborn, J. G., \& Connell, J. P. (1990). What it takes to do well in school and whether I've got it: A process model of perceived control and children's engagement and achievement in school. Journal of Education \& Psychology, 82(1), 22-32. https://doi.org/10.1037/0022-0663.82.1.22.

Walker, C. J. (2010). Experiencing flow: Is doing it together better than doing it alone? The Journal of Positive Psychology, 5(1), 3-11. https://doi.org/10.1080/17439760903271116.

Webster, J., Trevino, L. K., \& Ryan, L. (1993). The dimensionality and correlates of flow in human-computer interactions. Computers in Human Behavior, 9(4), 411-426. https://doi.org/10.1016/0747-5632(93)90032-N.

Wilkerson, L. (Ed.). (1996). Bringing problem-based learning to higher education: Theory and practice: New directions for teaching and learning. San Francisco: Jossey-Bass. 